\title{
Evolution of the Elastic Properties of an Oilwell Cement Paste at Very Early Age under Downhole Conditions: Characterization and Modelling
}

\author{
M. Bourissai ${ }^{1,2}$, F. Meftah ${ }^{2,3}$, N. Brusselle-Dupend', É. Lécolier ${ }^{1}$ and G. Bonnet ${ }^{2 *}$ \\ 1 IFP Energies nouvelles, 1-4 avenue de Bois-Préau, 92852 Rueil-Malmaison cedex - France \\ 2 Université Paris-Est, Laboratoire Modélisation et Simulation Multi-Echelle, MSME, UMR 8208 CNRS, \\ 5 Boulevard Descartes, Champs sur Marne, 77454 Marne La Vallée Cedex 2 - France \\ 3 Current address: Laboratoire de Génie Civil et Génie Mécanique (LGCGM), \\ 20 avenue de buttes de Coësmes, 35708 Rennes Cedex - France \\ e-mail: guy.bonnet@univ-paris-est.fr \\ * Corresponding author
}

Résumé - Évolution des propriétés élastiques d'une pâte de ciment pétrolier au très jeune âge dans des conditions HP/HT : caractérisation expérimentale et modélisation - Une modélisation multiéchelle, couplée avec un modèle d'hydratation, est proposée pour prédire l'évolution des propriétés élastiques d'une pâte de ciment pétrolier au très jeune âge (jusqu'à un jour). Des résultats expérimentaux montrent que la pression appliquée (1-200 bar) pendant la prise a peu d'effet sur la cinétique d'hydratation contrairement à la température $\left(20-60^{\circ} \mathrm{C}\right)$. Le modèle d'hydratation retenu a été validé par des mesures calorimétriques. Les résultats de porosité déduits de ce modèle d'hydratation sont d'ailleurs cohérents avec des mesures de la porosité connectée effectuées à différents degrés d'hydratation. La modélisation multi-échelle par homogénéisation prend en compte l'évolution des fractions volumiques des constituants de la pâte de ciment au cours de l'hydratation. Le développement des propriétés élastiques du ciment pétrolier au très jeune âge obtenues avec ce modèle est en bon accord avec les mesures obtenues par la propagation d'ultrasons.

\footnotetext{
Abstract - Evolution of the Elastic Properties of an Oilwell Cement Paste at Very Early Age under Downhole Conditions: Characterization and Modelling - A multi-scale homogenization approach coupled with a hydration model is adopted to predict the bulk and shear moduli evolution of an oilwell cement paste at a very early age (up to one day). Calorimetric experiments were performed to be compared with the results of the kinetics model and also to study the pressure and temperature effects on the hydration kinetics. The homogenization model results are in agreement with the elastic moduli measurements obtained from propagation of ultrasonic waves.
} 


\section{INTRODUCTION}

In oil and gas wells construction, primary cementing technique consists in placing cement slurries into the annular space between the drilled rock formation and the steel casing. The cement paste then hardens to form a hydraulic seal preventing the migration of formation fluids through the annulus. The latter has to be especially well cemented because the cement sheath is submitted to various thermal and mechanical loadings from the drilling phase to the abandonment phase. The main future objective of this work is to pave the way for computing stress and strain states developing within the cement sheath during cement paste hydration; indeed the behaviour of the cement sheath can have a drastic impact on the long term integrity of the well. Over the past ten years, several papers were concerned with the long term mechanical durability of the cement sheath. However, until now there are no relevant physical and mechanical inputs that allow to evaluate the development of stress and strain states in the cement at very early age of hydration in oil or gas wells [1-4]. The monitoring of mechanical properties measurements of the cement paste at very early age under downhole conditions is not trivial due to the lack of instrumentation that can help curing and maintaining the cement paste under downhole conditions while testing for mechanical properties. Ultrasonic measurements initially used as an indicator of setting [5] were extended in order to provide dynamic mechanical properties at room temperature and atmospheric pressure [6-9], and also to study the early-stage cement paste properties [10-12]. These mechanical properties are generally much more difficult to measure at a very early age than later in the hydration process, as they are continuously changing during the measurement course. Recently, some static mechanical properties measurements $[13,14]$ were obtained by uniaxial compression and have been compared with dynamic mechanical properties obtained from ultrasonic propagation.

From another point of view, the material within the cement sheath is completely confined, which means that its final state is strongly dependent of the overall hydration process, even during the very early beginning of the hydration process. So, a prediction of the properties of the cement paste from the evolution of the concentration of its constituents is clearly desirable for engineers. Such kind of prediction was already provided in the past for the prediction of mechanical properties at an early age [15-21]. However, these studies are restricted to a period of hydration corresponding to relatively large values of concentration of hydrates. In our study, we are interested by the process occurring at the very beginning of the hydration process, the concentration of hydrates starting

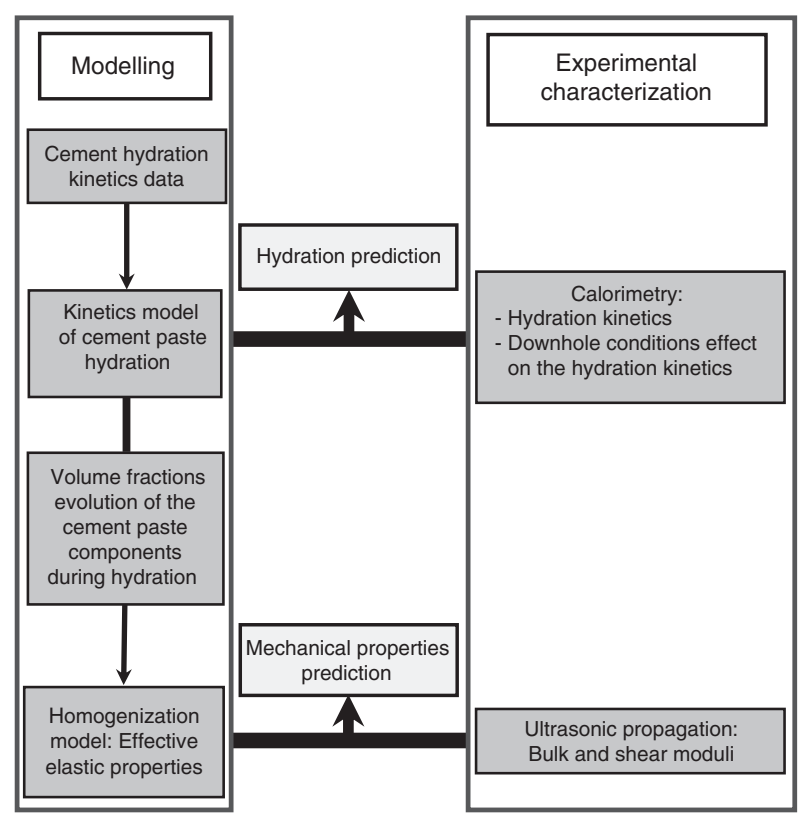

Figure 1

Workflow of this study.

from zero. This period of hydration is referred to as "very early age", for distinction of previous studies related to a later stage, usually referred to as "early age". However, the kind of models used at a later stage cannot be used, because it is necessary at a very early age to use a model which ensures the formation of a skeleton of hydrates for very small concentrations of hydrates, which is not $a$ priori provided by models used for the subsequent stages of hydration.

The present paper aims at characterizing and predicting the development of the elastic properties of a class $G$ oilwell cement paste at a very early age under downhole conditions (high pressure and high temperature, HP/HT). The main steps of the used approach are illustrated in Figure 1.

Section 1 concerns the homogenization of the mechanical behaviour of the cement paste at a very early age. For this purpose, a multi-scale approach, that uses the evolution of volume fractions of the different components of the cement paste during hydration, is used.

Section 2 deals with the necessary mechanical and chemical inputs for obtaining the evolution of volume fractions of the different components of the cement paste. The intrinsic mechanical properties of solid constituents are recovered from nano-indentation testing data coming from the literature, while the evolution of volume fractions is determined from a cement hydration kinetics model for the four clinker components of a class $\mathrm{G}$ oilwell cement. 
Section 3 is devoted to the experimental characterization of the class $\mathrm{G}$ oilwell cement paste. Semi-adiabatic calorimetric measurements are performed in order to validate the hydration kinetics model. Isotherm calorimetric measurements are also conducted to study downhole conditions effect on hydration kinetics. Dynamic moduli obtained by ultrasonic propagation measurements are presented and a comparison with the results of the homogenization model is finally provided in Section 4.

\section{PREDICTION OF ELASTIC PROPERTIES BY HOMOGENIZATION MODELLING}

From a general point of view, homogenization modelling is an upscaling approach which aims at predicting the properties of an heterogeneous material, from information on the distribution of its micro-structural components. So, several homogenization modelling methods were used for predicting the elastic behaviour of cement based materials during the hardening phase [15-22], based on the knowledge of the elastic properties and volume fractions of its constituents either during the hydration or in post hydration phase. The predictive capabilities of such upscaling approaches to determine the macroscopic elastic properties seem to be well established. The extension of such approaches to the prediction of the isothermal and not ageing viscoelastic behaviour of cement paste or concrete to estimate their creep during post hydration was also proposed from the use of the correspondence principle based on the Laplace-Carson transformation [22]. All these studies were not performed at the very early stage of cement paste but later during the hardening phase where the distribution of phases is drastically different from the one observed at the very early age. From another point of view, measurements during the quick evolution of the cement paste at a very early age are scarce and this paper will be restricted to the prediction of instantaneous elastic properties. A drastic difference between our work and previous studies on this subject is that the presence of the aqueous phase is predominant at a very early age and must be accounted for.

In this contribution, the study is particularly focused on the instantaneous properties of the cement paste during hydration through the choice of a microstructure model and of the related homogenization scheme.

\subsection{Homogenization in Linear Elasticity}

The principle of homogenization in linear elasticity is here briefly recalled from references [23, 24].
Let us consider a heterogeneous medium with $\mathrm{n}$ isotropic elastic phases whereof the concentrations $f_{i}$ with $i=1, \ldots, n$ evolve with time. A Representative Elementary Volume (REV) is considered in this medium, given by the domain $\Omega=\cup_{i}^{n} \Omega_{i}$ and the boundary $\partial \Omega$, where $\Omega_{i}$ correspond to the involved phases.

The elastic properties of the homogenized medium are obtained by linking the macroscopic strain $\mathbf{E}$ with the macroscopic stress $\Sigma$ :

$$
\Sigma=\langle\boldsymbol{\sigma}\rangle=\mathbf{C}_{\text {hom }}:\langle\boldsymbol{\varepsilon}\rangle=\mathbf{C}_{\text {hom }}: \mathbf{E}
$$

where $\boldsymbol{\sigma}=\boldsymbol{\sigma}(\boldsymbol{x})$ and $\boldsymbol{\varepsilon}=\boldsymbol{\varepsilon}(\boldsymbol{x})$ are the local values of the second order stress and strain tensors at location $\boldsymbol{x}$ and where the symbol $\langle\bullet\rangle$ stands for the volume average over the domain $\Omega$ of the quantity between brackets (assumed known at any point $\boldsymbol{x}$ of the REV). The fourth order tensor $\mathbf{C}_{\text {hom }}$ corresponds to the homogenized stiffness tensor, which can be written under the assumption of an isotropic effective elastic behaviour as:

$$
\mathbf{C}_{\text {hom }}=\left(\kappa_{\text {hom }}-\frac{2}{3} \mu_{\text {hom }}\right) \boldsymbol{\delta} \otimes \boldsymbol{\delta}+2 \mu_{\text {hom }} \mathbf{I}
$$

where $\kappa_{\text {hom }}$ and $\mu_{\text {hom }}$ are the bulk and shear moduli, $\boldsymbol{\delta}$ is the second order unit tensor and $\mathbf{I}$ is the fourth order identity tensor.

The main problem in homogenization is in predicting the local stress and strain distribution related to macroscopic stresses and strains; this process is called "localization". This is effected by applying suitable conditions at the boundary of the REV. In the following, a displacement field $\boldsymbol{u}=\mathbf{E} \cdot \boldsymbol{x}$ is applied at the external boundary $(\boldsymbol{x} \in \partial \Omega)$. Thanks to the linearity of the problem, the microscopic strain can be written as [25]:

$$
\boldsymbol{\varepsilon}(\boldsymbol{x}, t)=\mathbf{L}(\boldsymbol{x}, t): \mathbf{E}
$$

where $\mathbf{L}(\boldsymbol{x}, t)$ is a localization tensor which depends on time because of the evolution of the involved phases during hydration. Accordingly, the microscopic stress tensor can be written as:

$$
\boldsymbol{\sigma}(\boldsymbol{x}, t)=\mathbf{C}(\boldsymbol{x}): \mathbf{L}(\boldsymbol{x}, t): \mathbf{E}
$$

The effective elastic properties of the composite material can finally be related to the concentration $f_{i}$ of each phase and to its elastic properties $\mathbf{C}_{i}$ :

$$
\mathbf{C}_{\text {hom }}=\langle\mathbf{C}(\boldsymbol{x}): \mathbf{L}(\boldsymbol{x}, t)\rangle=\sum_{i} f_{i}(t) \mathbf{C}_{i}: \mathbf{L}_{i}\left(f_{i}, t\right)
$$

where $\mathbf{L}_{i}\left(f_{i}, t\right)=\langle\mathbf{L}(\boldsymbol{x}, t)\rangle_{\Omega_{i}}$ is the volume average per phase (over the sub-domain $\Omega_{i}$ ) of the localization tensor. The estimation of tensor $\mathbf{L}_{i}$ gives access to the required properties $\kappa_{\text {hom }}$ and $\mu_{\text {hom }}$. This estimation is made possible by the choice of a specific homogenization scheme which is based in the following on a simplified representation of the distribution of phases. 


\subsection{Choice of an Homogenization Scheme}

There are many homogenization schemes as thoroughly reviewed for example in the Milton's book on composite materials [24]. However, for the most complex schemes, the knowledge of the distribution of the different phases is necessary. So, our choice was to use the simplest scheme which is compatible with the physics underlying the hydration process. Among these schemes, the classical self-consistent scheme could not be used, because the formation of a continuous hydrate skeleton during hydration occurs at the very early stage of the process, for concentration of hydrates for which the percolation threshold is not predictable by the self-consistent scheme, unless by introducing form factors which are not adapted to hydrate particles. It is also emphasized again that in our study, the schemes used for later stages of hydration process could not be used in our study concerned by the very early age of hydration. Slightly more sophisticated schemes, such as Mori-Tanaka scheme or generalized-self-consistent schemes are able to guaranty a continuous hydrate skeleton at the very early stage of the process. Both schemes produce similar results at low concentrations but the field of application of the Mori-Tanaka scheme is more restricted at higher concentrations. So, our choice has been to use the Generalized Self-Consistent scheme (GSC).

For the most general expression of a GSC scheme, $n$ isotropic elastic phases are represented by a composite sphere containing layers considered as homogeneous. The interaction between such a composite sphere and the surrounding materials is approximated by the interaction with a material having effective properties in the outer part (as for the classical self-consistent scheme) numbered $(n+1)$ (Fig. 2). Each constituting phase $i$ is considered as elastically isotropic and characterized by its bulk and shear moduli $\left(\kappa_{i}, \mu_{i}\right)$ and its volume fraction $f_{i}=\left(R_{i}^{3}-R_{i-1}^{3}\right) / R_{n}^{3}$.

Assuming that the REV is submitted at infinity to a displacement $\boldsymbol{u}=\mathbf{E} . \boldsymbol{x}$ related to the macroscopic mean strain $\mathbf{E}$, the effective properties $\kappa_{\text {hom }}$ and $\mu_{\text {hom }}$ are obtained from closed-form expressions of elastic properties and concentrations of constituent phases, as described in [27] and briefly recalled in Appendix A.

\subsection{Microstructure Evolution of the Cement Paste during Hydration}

The morphological properties of the hydrating cement paste have to be considered with care to define a relevant homogenization scheme. When anhydrous cement is mixed with water, the cement paste can be seen at a very early age as a suspension. Next, the hydration leads to

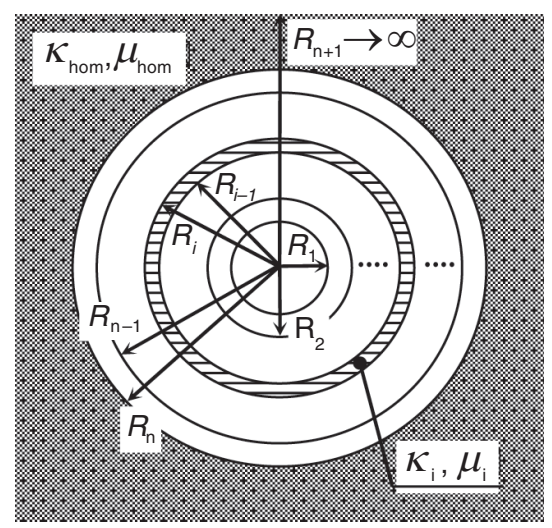

Figure 2

Generalized self-consistent scheme of a multiphase medium according to [27].

the nucleation and to the growth of a multi-components and porous assembly of hydrates phase which produces a gradual increase of the mechanical properties of the hardening cement paste due to the development of a cohesive solid skeleton. The progressive development of the hydrated compounds induces a gradual decrease of the aqueous and anhydrous phases as illustrated in Figure 3. The aqueous phase is mainly present in the C-S-H gel porosity and in a (totally or partially) filled capillary porosity, interspersed in the hydrates network.

In the context of the present study, the cement sheath is assumed continuously supplied with water coming from the nearby saturated rock formations.

Representing schematically the evolutionary microstructure of the cement paste during hydration is not obvious. Nevertheless, the representation of this microstructure is necessary to estimate the homogenized mechanical properties. The main phases in presence are hydrates, anhydrous phase and aqueous phase and, having in view to use the GSC scheme, it is necessary to affect elastic properties at each part of the composite sphere. It is tempting to use a composite sphere made of three parts (aqueous phase, hydrates and anhydrous phase). Unfortunately, none of the different definitions of composite spheres can be considered as realistic for representing the main features of the geometrical distribution of phases, the main principle being that as soon as the hydration process begins, the anhydrous parts are surrounded by hydrates (Fig. 4).

The scheme which has been finally retained is described in Figure 5. It comprises a connected external spherical layer made of hydrates (containing a part of anhydrous phase), in contact with a spherical layer containing the aqueous phase, itself containing a central composite 


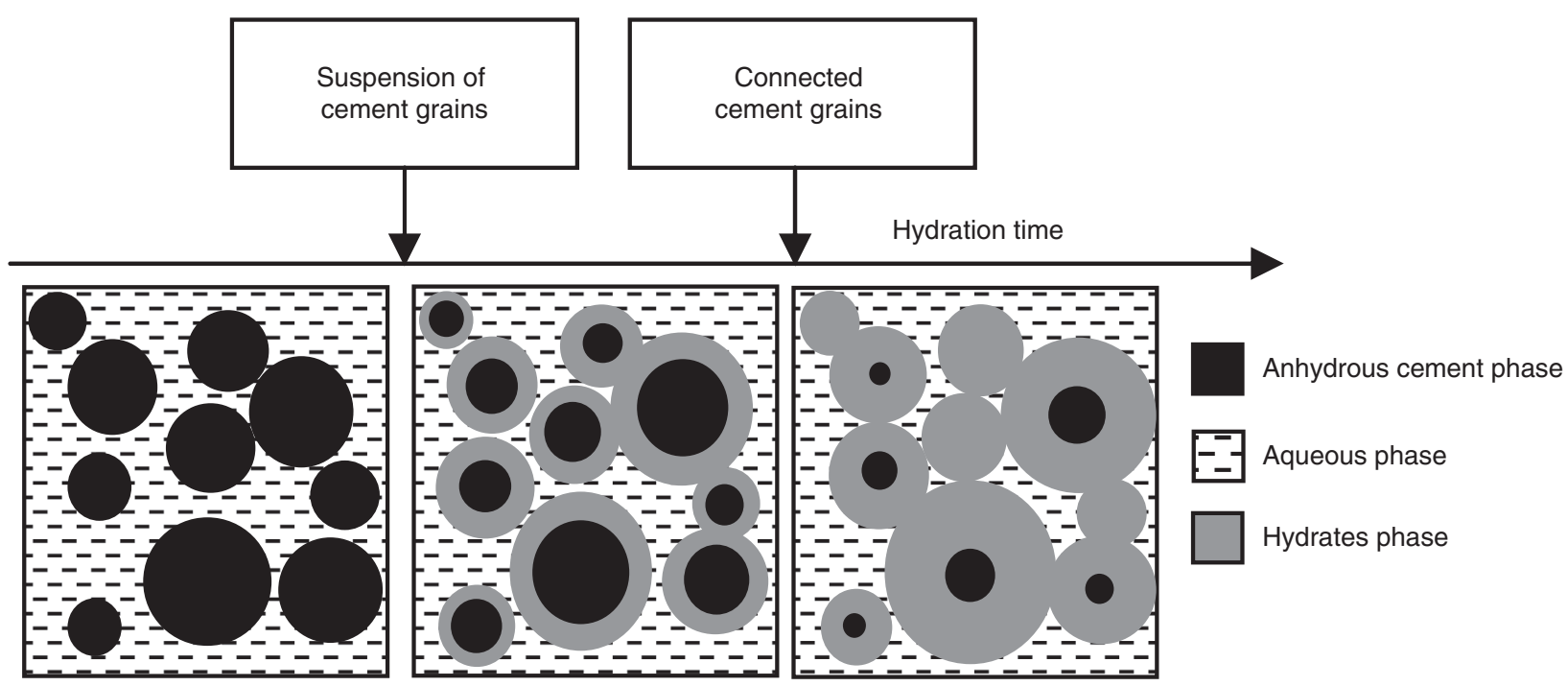

Figure 3

Evolution of the constituents of the cement paste during early age hydration.

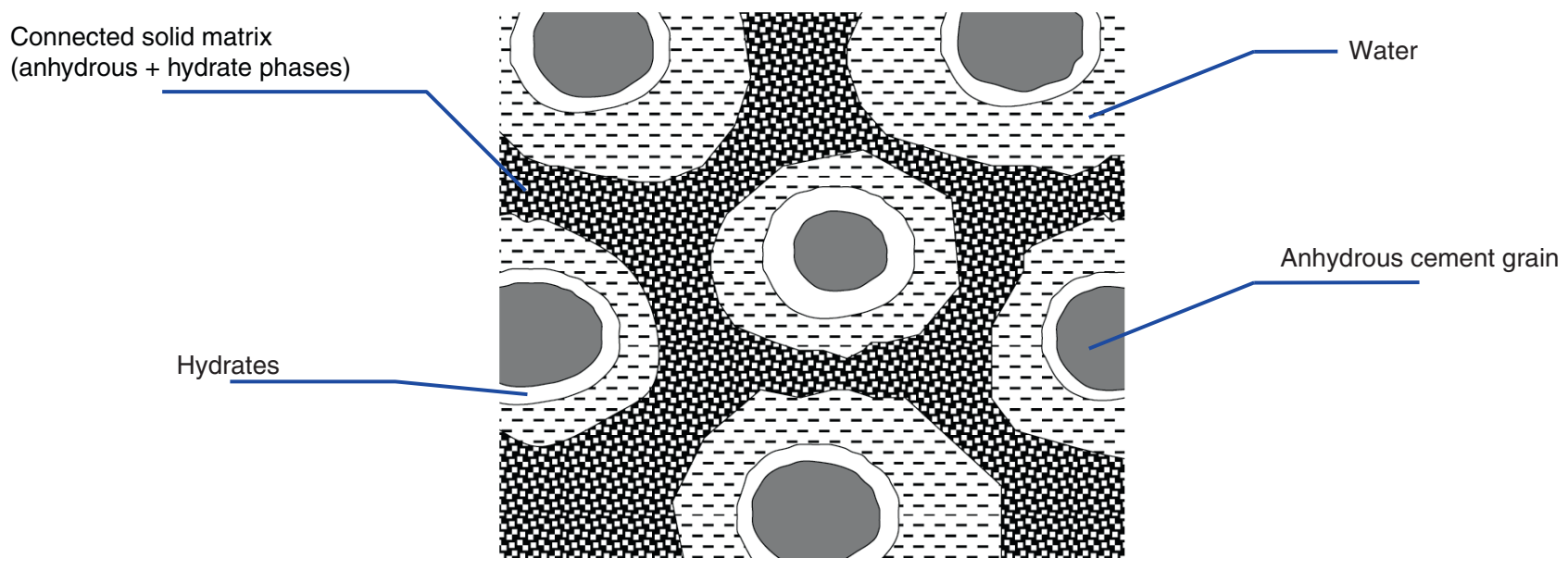

Figure 4

Representation of the morphological model of the hydrating cement paste during the second step of Figure 3.

sphere made of a hydrate spherical layer surrounding a central sphere containing the anhydrous material. However, it is worthwhile to mention that the hydrates themselves are not homogeneous and it is necessary to account for this feature for obtaining the properties of hydrates, as described in the following subsection.

\subsection{Multi-Scale Analysis}

The homogenization process applied to the cement paste requires to take into account some parameters which are defined at different scales. Such scales (Fig. 5) can be defined as follows:

\section{Scale 0: C-S-H Gel}

At the lowest scale, the C-S-H gel is heterogeneous. At this scale, some mechanical properties of the C-S-H gel are accessible by mechanical testing, i.e. nano-indentation $(T a b .1)$. The C-S-H gel exists under two different forms: a Low Density (LD) C-S-H with a porosity of roughly $37 \%$ and a High Density (HD) gel of around $24 \%$ of porosity [26]. The C-S-H gel is the dominant 


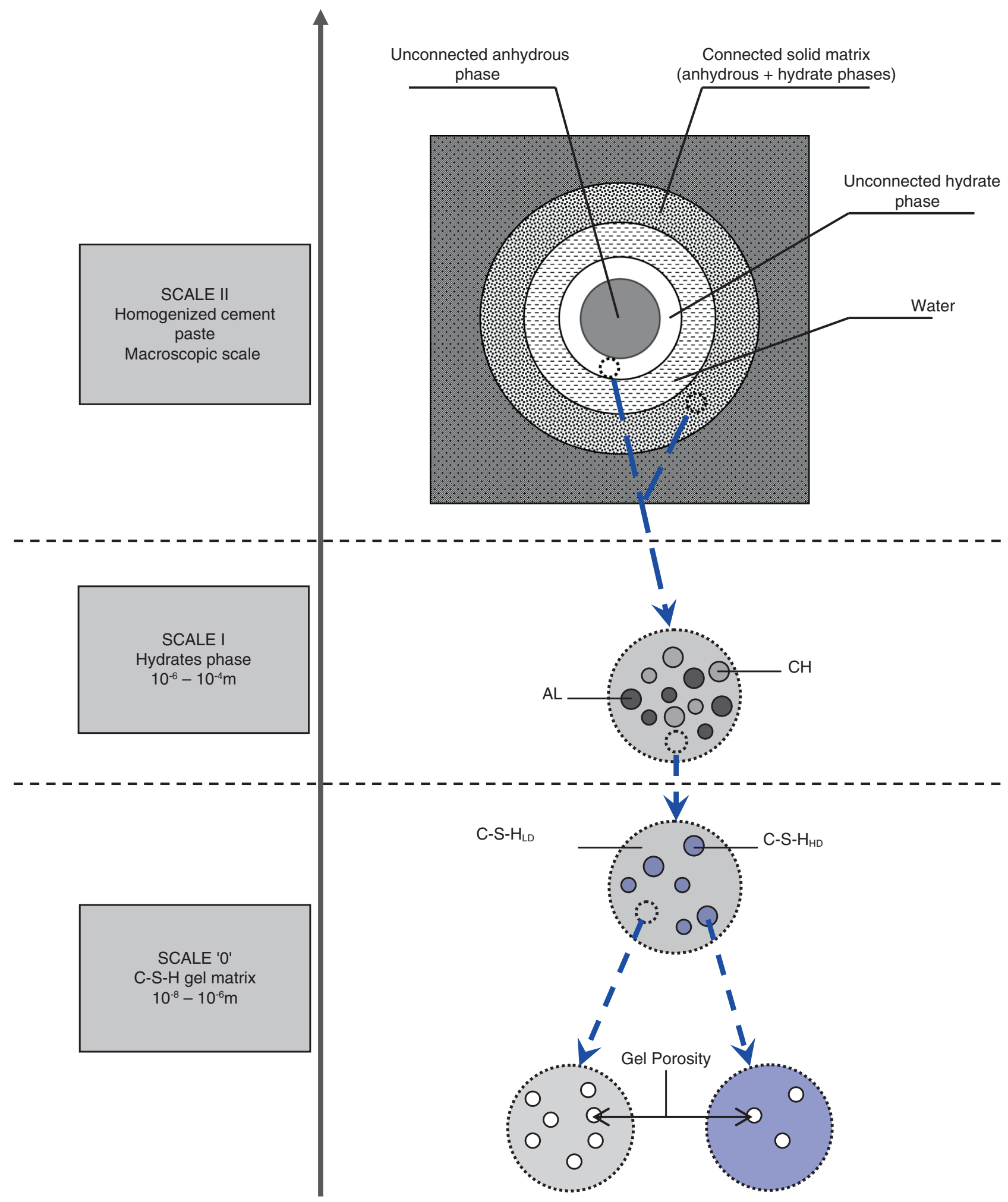

Figure 5

Upscaling method applied to the cement paste. 
TABLE 1

Intrinsic elastic properties of the cement paste components

\begin{tabular}{c|c|c|c|c}
\hline & & \multicolumn{3}{|c}{ Elastic constants } \\
\hline \multirow{2}{*}{ Anhydrous cement: $x$} & & $E(\mathrm{GPa})$ & $v(-)$ & References \\
\cline { 2 - 5 } & $\mathrm{C}_{3} \mathrm{~S}$ & 135 & 0.3 & Monteiro and Chang [29] \\
\cline { 2 - 5 } & $\mathrm{C}_{2} \mathrm{~S}$ & 140 & - & Acker [30] \\
\cline { 2 - 5 } & $\mathrm{C}_{3} \mathrm{~A}$ & 145 & - & Velez et al. [31] \\
\hline \multirow{2}{*}{ Hydrates: $z$ and $y$} & $\mathrm{C}_{4} \mathrm{AF}$ & 125 & 0.24 & Constantinides and Ulm \\
{$[32]$}
\end{tabular}

component of the forming cement paste skeleton and may be regarded at the upper scale as a homogeneous matrix connected with the other phases.

\section{Scale I: Hydrates Phase}

This scale is associated with the hydrates phase in Figure 5 which is seen as a composite phase formed by a C-S-H matrix surrounding portlandite $(\mathrm{CH})$ and aluminates (AL).

\section{Scale II: Homogenized Cement Paste}

This is the upper scale corresponding to macroscopic scale, that is the scale at which the elastic properties have to be determined during the hydration process starting from the intrinsic elastic properties of individual components in these three defined scales and from their varying volumetric concentrations.

\subsection{Estimation of the Effective Elastic Properties}

The volume fractions of all phases can be deduced at each stage of the hydration process. However, the composite spherical cell of Figure 5 is not completely defined because hydrated and anhydrous phases appear in two different parts of the composite sphere: one part named "connected solid matrix" being the external spherical layer, and the second one named "unconnected hydrate/anhydrous phases" comprising the internal sphere and its surrounding layer.

Some assumptions are therefore necessary to define the concentrations of all phases. First (assumption 1), without complementary information, the ratios between volume fraction of hydrates and of anhydrous materials are assumed to be the same within the two parts mentioned above. Next, an important point is to characterize the ratio between the volume fractions of connected $\left(f_{c}\right)$ and unconnected $\left(f_{u}\right)$ parts.

Let us consider the volume fractions $f_{c}$ and $f_{u}$ of both parts. It is obvious that $f_{c}$ is null at the beginning of the hydration process and equal to 1 at the end of the hydration process.

Now, let us consider the ratio $\frac{f_{c}}{f_{u}+f_{w}}$ where $f_{w}$ is the volume fraction of water. This ratio tends to 0 when the hydration ratio is null and becomes very large when the hydration ratio tends to 1 . A simple way to ensure this property (assumption 2) is to assume that:

$$
\frac{f_{c}}{f_{u}+f_{w}}=\alpha \frac{\xi}{1-\xi}
$$

where $\alpha$ is a constant parameter and $\xi$ is the hydration ratio whose definition is recalled in Section 2. Indeed, if the hydration is complete $(\xi=1)$ and if the initial quantity of water is adjusted so that it is completely consumed at the end of hydration, all the water and the anhydrous materials are consumed at this stage $\left(f_{w}=f_{u}=0\right)$. And therefore both ratios tend to infinity. At the beginning of hydration $(\xi=0)$ there is no hydrates and no connected materials and therefore $f_{c}=0$. Under the previous assumptions, these two limit cases are consistent with the use of the previous relationship.

Finally, the use of assumption 1 for a given hydration ratio allows the computation of the ratio of hydrates and anhydrous components in the different spheres of Figure 5. It produces the ratio of the radii of the smallest spheres and the properties of the material contained in 
the upper layer of the figure. The combination of assumptions 1 and 2 allows the computation of the radii of all spheres.

Finally, this set of assumptions allows the computation of all concentrations of phases in the composite sphere model and leads to the theoretical estimation of effective properties as follows.

For a given value of $\alpha$, all volume fractions of the constituents are known for any hydration ratio. Knowing the elastic properties of hydrated and anhydrous phases (see next subsection), the computation of elastic properties is performed in two steps.

A first step is to obtain the elastic properties of the "connected solid matrix". These properties are obtained by using the GSC scheme (Appendix $A$ ) for two phases $(n=2)$ with one central sphere made of anhydrous phase and an external spherical layer made of hydrates, the radii of spheres being obtained as explained before by using assumption 1 .

In a second step these properties are introduced in the full 4-phases GSC scheme for obtaining the overall properties, the radii of the spheres being obtained from the hydration ratio as previously. At this stage, the equations of Appendix A are again used for $n=4$. These equations produce the overall effective elastic moduli of the cement paste.

\section{MATERIAL INPUT DATA}

Computing the homogenized bulk and shear moduli $\left(\kappa_{\text {hom }}, \mu_{\text {hom }}\right)$ of the hydrating cement paste requires the knowledge of the intrinsic elastic moduli of the cement paste components at the different defined scales (Fig. 5) and their volume fractions evolution during hydration. The elastic properties at the lowest scales are assumed to be intrinsic and taken from the literature based on nano-indentation tests.

A first part of this section describes the simplified homogenization scheme which is used for obtaining the "mean" properties of hydrated and anhydrous phases, knowing the properties of their constituents at a lower scale.

The second part of this section describes the hydration model which provides the evolution of the volume fractions of all phases during hydration.

\subsection{Mechanical Data}

The hydrate phase contains all hydrates which are formed during the hydration process. It is not possible to account for the distribution of all these parts. However, the contrast between their mechanical properties is not too high and the effect of the microstructure is reduced, which induces that different homogenization processes produce similar results. In addition, it is wellknown that the effective bulk modulus and shear modulus are strictly comprised between two bounds made of their volume mean value and of their volume harmonic mean value. So a convenient simplified estimation of the mean properties at this stage is provided by the mean between these two bounds.

This estimation is used thereafter. Indeed, at the scale ' 0 ' the elastic properties of the C-S-H matrix $\left(\kappa_{C-S-H}, \mu_{C-S-H}\right)$ are first determined by volume averages obtained from the two types of C-S-H $\left(\kappa_{z}, \mu_{z}\right)$ with $z=L D$ C-S-H and $H D$ C-S-H:

$$
\left(\kappa_{C-S-H}, \mu_{C-S-H}\right)=\frac{\sum_{z} \hat{f}_{z}(t)\left(\kappa_{z}, \mu_{z}\right)+\left(\sum_{z} \frac{\hat{f}_{z}(t)}{\left(\kappa_{z}, \mu_{z}\right)}\right)^{-1}}{2}
$$

where $\hat{f}_{\mathrm{z}}$ is the volume fraction of each type of C-S-H in the C-S-H matrix. At the upper scale, the same estimation from volume averages is used to determine the elastic properties of the hydrates phase $\left(\kappa_{h}, \mu_{h}\right)$ from the elastic properties of each hydrate component $\left(\kappa_{y}, \mu_{y}\right)$ with $y=$ homogenized C-S-H at the scale 0 , portlandite $(\mathrm{CH})$ and aluminates $(\mathrm{AL})$ :

$$
\left(\kappa_{h}, \mu_{h}\right)=\frac{\sum_{y} \hat{f}_{y}(t)\left(\kappa_{y}, \mu_{y}\right)+\left(\sum_{y} \frac{\hat{f}_{y}(t)}{\left(\kappa_{y}, \mu_{y}\right)}\right)^{-1}}{2}
$$

in which $\hat{f}_{y}$ is the volume fraction of each hydrated component in the hydrates phase. Similarly, the elastic properties of the anhydrous cement $\left(\kappa_{a}, \mu_{a}\right)$ are determined from the elastic properties of each anhydrous component $\left(\kappa_{x}, \mu_{x}\right)$ with $x=\mathrm{C}_{3} \mathrm{~S}, \mathrm{C}_{2} \mathrm{~S}, \mathrm{C}_{3} \mathrm{~A}$ and $\mathrm{C}_{4} \mathrm{AF}$ :

$$
\left(\kappa_{a}, \mu_{a}\right)=\frac{\sum_{x} \hat{f}_{x}(t)\left(\kappa_{x}, \mu_{x}\right)+\left(\sum_{x} \frac{\hat{f}_{x}(t)}{\left(\kappa_{x}, \mu_{x}\right)}\right)^{-1}}{2}
$$

where $\hat{f}_{x}$ is the volume fraction of each anhydrous component in the anhydrous cement.

With regard to the elastic moduli of the solid phases, Table 1 gives the available data at these scales in terms of Young's modulus E and of Poisson's ratio obtained from literature. Unfortunately, there is a lack of the elastic properties of aluminates. Since the elastic properties of $\mathrm{C}_{3} \mathrm{~S}$ were carefully measured, Poisson's ratio value of $\mathrm{C}_{3} \mathrm{~S}$ is simply used for $\mathrm{C}_{3} \mathrm{~A}$ and $\mathrm{C}_{4} \mathrm{AF}$. For the aluminate hydrates, it is assumed that their 
properties are similar to the elastic properties of the C-S$\mathrm{H}$ matrix provided by Equation (7). Using the values obtained from Table 1, the elastic bulk and shear moduli for the solid compounds $\left(\kappa_{x}, \mu_{x}, \kappa_{y}, \mu_{y}, \kappa_{z}, \mu_{z}\right)$ are computed according to the classical relationships of elasticity. This set must be completed by the elastic properties of the aqueous phase, whose bulk modulus is $\kappa_{\mathrm{w}}\left(20^{\circ} \mathrm{C}\right)=2.18 \mathrm{GPa}$ and $\kappa_{\mathrm{w}}\left(60^{\circ} \mathrm{C}\right)=2.25 \mathrm{GPa}$ [28], its shear modulus being null.

\subsection{Data Coming from the Chemical Hydration Model}

The volume fractions of the different phases inside the cement paste are continuously evolving during the hydration process. So, the main objective of this section is to provide the volume fractions evolution of the phases during the hydration process. This requires two steps:

- the description of the evolution of the hydration degree from kinetics laws of reactions related to the hydration of each anhydrous phase;

- the determination of the evolution of volume fractions of associated hydration products together with the progressive decrease of anhydrous components and aqueous phase.

\subsubsection{Hydration Model}

The hydration process of each compound $x$ is expressed in terms of its degree of hydration $\xi_{x}$ which is one minus the ratio of the unreacted mass $m_{x}$ of each anhydrous component to its initial mass $m_{x}^{0}$ :

$$
\xi_{x}(t)=1-\frac{m_{x}(t)}{m_{x}^{0}}
$$

In this subsection, kinetics laws based on chemical affinity are used for the description of the cement hydration [20]. These laws were found suitable for the prediction of the cement hydration during all hydration stages and easily incorporated within the framework of a chemically reactive [33] porous medium.

Therefore, the cement hydration kinetics reads:

$$
\frac{d \xi_{x}}{d t}=\frac{1}{\tau_{x}(T, \phi)} \tilde{A}_{x}\left(\xi_{x}\right)
$$

where $\tilde{A}_{x}(-)$ is the normalized chemical affinity, $\tau_{x}($ hour $)$ denotes the characteristic time of the chemical reaction, which depends on the temperature $T$, the current Blaine surface area $\phi$, the type of clinker mineral and the water to cement ratio $w / c$.

Furthermore, dependence of the hydration reaction on temperature is considered to be described according to Arrhenius equation [34] by reducing the characteristic time of the reaction as:

$$
\tau_{x}(T, \phi)=\tau_{x}\left(T_{0}, \phi_{0}\right) \frac{\phi_{0}}{\phi} \exp \left(\frac{E_{a}^{x}}{R}\left(\frac{1}{T}-\frac{1}{T_{0}}\right)\right)
$$

where $\tau_{x}\left(T_{0}, \phi_{0}\right)$ is the characteristic time of the chemical reaction [15] at the reference temperature $T_{0}=293 \mathrm{~K}$, $\phi_{0}=3602 \mathrm{~cm}^{2} \cdot \mathrm{g}^{-1}$ is a reference fineness of cement, $E_{a}^{x}$ is the activation energy of each component $x$ and $R$ is the gas constant.

Moreover, experimental results obtained from isothermal calorimetric measurements with DSC (Fig. $8 a$ in Sect. 3.1.1) have allowed to verify the existence of three hydration stages in the period concerned in our study. The normalized affinity takes then three particular expressions according to the stage as reported in [20]:

1. Induction stage, at which the dissolution of clinker occurs.

2. Growth stage characterized by a nucleation process accompanied by reaction acceleration and formation of hydration products.

3. Diffusion stage which corresponds to the process during which ions diffuse through a thickening layer of hydration products toward anhydrous cement grains.

During the induction stage $\left(t<t_{x}^{0}\right.$ and $\left.\xi_{x}(t)<\xi_{x}^{0}\right)$, the reaction is very slow, which allows to assume that it does not evolve practically during this stage. In this case, the chemical affinity is assumed constant, which implies $\tilde{A}_{x}=1[20,21]$. The stage duration, noted $t_{x}^{0}$, reads:

$$
t_{x}^{0}=\xi_{x}^{0} \cdot \tau_{x}(T, \phi)
$$

where $\xi_{x}^{0}$ is the critical degree of hydration at the end of the pre-induction which is characterized by an instantaneous release of heat. The degree of hydration during this stage is then given by:

$$
\xi_{x}(t)=\xi_{x}^{0} H(t)
$$

where $H(t)$ is the Heaviside step function.

During the growth stage $\left(t_{x}^{0}<t<t_{x}^{g}\right.$ and $\left.\xi_{x}^{0}<\xi_{x}(t)<\xi_{x}^{g}\right)$ of upper limit-time $t_{x}^{g}$, the normalized affinity $\tilde{A}_{x}^{g}$ is given by Avrami's model:

$$
\tilde{A}_{x}^{g}\left(\xi_{x}\right)=\frac{1-\xi_{x}}{\left(-\ln \left(1-\xi_{x}\right)\right)^{K_{x}^{-1}-1}}
$$

In addition, the characteristic time associated with the growth stage writes:

$$
\tau_{x}^{g}\left(T_{0}\right)=\frac{1}{K_{x} \cdot k_{x}}
$$


The parameter $K_{x}$ defines reaction order whereas $k_{x}$ represents the rate constant.

During the diffusion stage $\left(t>t_{x}^{g}\right.$ and $\left.\xi_{x}(t)>\xi_{x}^{g}\right)$, the normalized affinity $\tilde{A}_{x}^{d}$ is given by the model of Fuji and Kondo:

$$
\tilde{A}_{x}^{d}\left(\xi_{x}\right)=\frac{\left(1-\xi_{x}\right)^{2 / 3}}{\left(1-\xi_{x}^{d}\right)^{1 / 3}-\left(1-\xi_{x}\right)^{1 / 3}}
$$

where $\xi_{x}^{d}$ is the critical hydration degree at the end of the growth stage.

The characteristic time $\tau_{x}^{d}\left(T_{0}\right)$ is obtained from the diffusion coefficient $D$ and from the initial radius $r$ of the cement grain, by:

$$
\tau_{x}^{d}\left(T_{0}\right)=\frac{r^{2}}{3 D}
$$

The values of parameters used in this paper are summarized in Table 2. They were interpolated from data published in [20]. The diffusion coefficient values were deduced from the fitting of the present hydration model to the experimental hydration data of Escalante-Garcia and Sharp [35] for each cement component.

Finally the overall degree of hydration $\xi(t)$ is obtained from the values of the partial hydration degree $\xi_{x}(t)$ of each anhydrous cement component $x$ as follows:

$$
\xi(t)=\frac{\sum_{x} m_{x}^{0} \xi_{x}(t)}{m_{a}^{0}}=\sum_{x} f_{x}^{m} \xi_{x}(t)
$$

where $m_{a}^{0}=\sum_{x} m_{x}^{0}$ is the initial total mass of the anhydrous cement and $f_{x}^{m}$ is the initial mass fraction of each anhydrous component.

An alternative estimation, $\xi_{Q}$, of the hydration degree can be directly related to results of $Q(t)$ obtained from calorimetric measurement (semi-adiabatic) which will be used thereafter. It is given by:

$$
\xi_{Q}(t)=\frac{Q(t)}{Q^{\infty}}
$$

where:

$$
Q^{\infty}=\sum_{x} f_{x}^{m} q_{x}^{\infty}
$$

$Q(t)$ is the current heat of hydration, $Q^{\infty}$ is its asymptotic value released at full hydration $\left(\xi_{Q}=1\right)$. It is important to note that $Q^{\infty}$ depends on $q_{x}^{\infty}$, the corresponding asymptotic value for each component $x$, whose experimental data show a certain dispersion in the literature (Tab. 3).

Equation (22) shows an equivalent expression of Equation (20) with $\mathrm{Q}(\mathrm{t})$ deduced from the current hydration heat of each component $x$.

\begin{tabular}{|c|c|c|c|c|c|}
\hline & & \multicolumn{4}{|c|}{ Anhydrous cement components } \\
\hline & Model parameters & $\mathrm{C}_{3} \mathrm{~S}$ & $\mathrm{C}_{2} \mathrm{~S}$ & $\mathrm{C}_{3} \mathrm{~S}$ & $\mathrm{C}_{4} \mathrm{AF}$ \\
\hline & $\mathrm{E}_{a} / \mathrm{R}(\mathrm{K})$ & 4500 & 2500 & 5500 & 4200 \\
\hline & $\xi_{x}^{0}(-)$ & 0.02 & 0.00 & 0.04 & 0.04 \\
\hline & $K_{x}(-)$ & 1.78 & 1.01 & 1.04 & 2.34 \\
\hline & $\xi_{x}^{d}(-)$ & 0.6 & 0.6 & 0.6 & 0.6 \\
\hline \multirow[t]{3}{*}{$23^{\circ} \mathrm{C}$} & $\tau_{x}^{g}(\mathrm{~h})$ & 12.21 & 69.13 & 48.43 & 22.69 \\
\hline & $\tau_{x}^{d}(\mathrm{~h})$ & 5041.53 & 27013.31 & 695.73 & 72773.18 \\
\hline & $D\left(\mathrm{~cm}^{2} \cdot \mathrm{h}^{-1}\right)$ & $1.2 \times 10^{-10}$ & $1.0 \times 10^{-11}$ & $3.5 \times 10^{-10}$ & $3.5 \times 10^{-12}$ \\
\hline \multirow[t]{3}{*}{$60^{\circ} \mathrm{C}$} & $\tau_{x}^{g}(\mathrm{~h})$ & 2.26 & 27.04 & 6.15 & 4.70 \\
\hline & $\tau_{x}^{d}(\mathrm{~h})$ & 1592.07 & 1472.67 & 294.53 & 9817.78 \\
\hline & $D\left(\mathrm{~cm}^{2} \cdot \mathrm{h}^{-1}\right)$ & $18.5 \times 10^{-11}$ & $20.0 \times 10^{-11}$ & $1.0 \times 10^{-9}$ & $3.0 \times 10^{-11}$ \\
\hline
\end{tabular}

$$
\xi_{Q}(\mathrm{t})=\frac{\sum_{x} f_{x}^{m} q_{x}^{\infty} \xi_{x}(t)}{\sum_{x} f_{x}^{m} q_{x}^{\infty}}
$$

TABLE 2

Hydration kinetics model parameters for $w / c=0.44$ 
TABLE 3

Asymptotic values of hydration heat for each component $x$

\begin{tabular}{c|c|c|c|c}
\hline & \multicolumn{4}{|c}{ The Heat of hydration (J.g $\left.{ }^{-1}\right)$} \\
\hline & $q_{\mathrm{C}_{3} \mathrm{~S}}^{\infty}$ & $q_{\mathrm{C}_{2} \mathrm{~S}}^{\infty}$ & $q_{\mathrm{C}_{3} \mathrm{~A}}^{\infty}$ & $q_{\mathrm{C}_{4} \mathrm{AF}}^{\infty}$ \\
\hline Taylor [36] & 517 & 262 & 1144 & 418 \\
\hline Chougnet et al. [37] & 520 & 70 & 1670 & 725 \\
\hline
\end{tabular}

\subsubsection{Volume Fractions Evolution during the Hydration Process}

The hydration kinetics, Equations (11)-(18), for each anhydrous cement component are used for determining the evolution of the volume fractions related to the different phases of the cement paste during hydration.

At each time $t$, the volumes of remaining anhydrous cement $V_{a}$, of water $V_{w}$, of the formed hydrates containing gel porosity $V_{h}$ and of capillary porosity $V_{p}$ are determined. The volume of the cement paste $V_{c}$ is then given by:

$$
V_{c}(t)=V_{a}(t)+V_{w}(t)+V_{h}(t)+V_{p}(t)
$$

In this work, the cement paste volume is assumed constant during hydration, which means that bulk shrinkage is neglected with regard to volume variation:

$$
V_{c}(t)=V_{c}^{0}=V_{a}^{0}+V_{w}^{0}
$$

where $V_{a}^{0}$ and $V_{w}^{0}$ are the initial volumes of anhydrous cement and water in the mixture.

The volume fractions for each phase of the cement paste are given by:

$f_{a}(t)=\frac{V_{a}(t)}{V_{c}^{0}} ; f_{w}(t)=\frac{V_{w}(t)}{V_{c}^{0}} ; f_{h}(t)=\frac{V_{h}(t)}{V_{c}^{0}} ; f_{p}(t)=\frac{V_{p}(t)}{V_{c}^{0}}$

with $f_{a}(t)+f_{w}(t)+f_{h}(t)+f_{p}(t)=1$.

More suitable forms of volume fraction expressions can be obtained by considering stoichiometry of the hydration reactions of the four main cement components $\mathrm{C}_{3} \mathrm{~S}, \mathrm{C}_{2} \mathrm{~S}, \mathrm{C}_{3} \mathrm{~A}, \mathrm{C}_{4} \mathrm{AF}$ :

$$
\begin{aligned}
& \mathrm{C}_{3} \mathrm{~S}+5.3 \mathrm{H} \rightarrow 0.5 \mathrm{C}_{3.4} \mathrm{~S}_{2} \mathrm{H}_{8}+1.3 \mathrm{CH} \\
& \mathrm{C}_{2} \mathrm{~S}+4.3 \mathrm{H} \rightarrow 0.5 \mathrm{C}_{3.4} \mathrm{~S}_{2} \mathrm{H}_{8}+0.3 \mathrm{CH} \\
& \mathrm{C}_{4} \mathrm{AF}+2 \mathrm{CH}+10 \mathrm{H} \rightarrow 2 \mathrm{C}_{3}(\mathrm{~A}, \mathrm{~F}) \mathrm{H}_{6} \text { (Hydrogarnet) } \\
& \mathrm{C}_{3} \mathrm{~A}+3 \overline{C S}_{2}+26 \mathrm{H} \rightarrow \mathrm{C}_{6} \overline{A S}_{3} \mathrm{H}_{32} \text { Ettringite }(\mathrm{AFt})
\end{aligned}
$$

$$
\begin{aligned}
& \mathrm{C}_{3} \mathrm{~A}+0.5 \mathrm{C}_{6} \mathrm{AS}_{3} \mathrm{H}_{32}+ 2 \mathrm{H} \rightarrow 1.5 \mathrm{C}_{4} \mathrm{~A} \overline{\mathrm{S}} \mathrm{H}_{12} \\
& \text { Monosulfate }(\mathrm{AFm}) \\
& \mathrm{C}_{3} \mathrm{~A}+\mathrm{CH}+12 \mathrm{H} \rightarrow \mathrm{C}_{4} \mathrm{AH}_{13} \text { Calcium aluminate hydrate }
\end{aligned}
$$

The hydration reactions of $\mathrm{C}_{3} \mathrm{~A}$ have to be particularly considered with care because they occur at different stages in the presence of gypsum and overlap each other. The ettringite which is a stable product is first formed (Eq. 29), and when the gypsum $\left(\mathrm{CS}_{\mathrm{S}}{ }_{2}\right)$ is consumed, the ettringite becomes unstable and further hydration yields the monosulfate $(E q .30)$. Then, calcium aluminate hydrate may be formed $(E q .31)$ if $\mathrm{C}_{3} \mathrm{~A}$ is not completely consumed after the formation of $\mathrm{AFm}(\mathrm{Eq} .30)$. The $\mathrm{C}_{3} \mathrm{~A}$ reactions rate also depends on several factors such as temperature, $w / c$ ratio and grain size [36]. Furthermore, the initial mass of $\mathrm{C}_{3} \mathrm{~A}$ represents only $2 \%$ of the initial mass of the studied anhydrous cement (Tab. 4). Consequently, an approximation is made by considering that $\mathrm{C}_{3} \mathrm{~A}$ is assimilated to $\mathrm{C}_{4} \mathrm{AF}$ and only the hydration reaction of the $\mathrm{C}_{4} \mathrm{AF}$ which forms the hydrogarnet $(E q .28)$ is considered to describe the volume fraction evolution of the aluminate hydrates.

According to [20], the volume fractions of the different phases of the cement paste can finally be written in terms of stoichiometric ratios $\theta$ of the chemical reactions Equations (26)-(31), mass densities $\rho$ and molar masses $M$ :

$$
\begin{gathered}
f_{a}(t)=f_{a}^{0} \sum_{x}\left(1-\xi_{x}(t)\right) f_{x}^{0} \frac{\rho_{x}}{\rho_{a}} \\
f_{w}(t)=f_{w}^{0}-f_{a}^{0} \sum_{x}\left(\theta_{w}^{x} f_{x}^{0} \frac{\rho_{x}}{\rho_{w}} \frac{M_{w}}{M_{x}} \xi_{x}(t)\right) \\
f_{h}(t)=f_{a}^{0} \sum_{y}\left(\sum_{x} \theta_{y}^{x} \frac{M_{y}}{M_{x}} \frac{\rho_{x}}{\rho_{h}} f_{x}^{0} \xi_{x}(t)\right) \\
f_{p}(t)=1-f_{w}(t)-f_{a}(t)-f_{h}(t)
\end{gathered}
$$

Figure 6 presents the volume fractions evolution during the hydration of a class $\mathrm{G}$ cement paste. The consumption of the anhydrous cement and water during the hydration reactions results in the formation of 
TABLE 4

Physical properties and mineral composition of the class $\mathrm{G}$ cement

\begin{tabular}{|c|c|c|}
\hline & & Class $\mathrm{G}$ \\
\hline \multirow[t]{2}{*}{ Physical properties } & $\begin{array}{l}\text { Surface area } \\
\left(\mathrm{cm}^{2} \cdot \mathrm{g}^{-1}\right)\end{array}$ & 3160 \\
\hline & $\begin{array}{l}\text { Grains average } \\
\text { radium }(\mathrm{cm})\end{array}$ & $9.4 \times 10^{-4}$ \\
\hline \multirow{4}{*}{$\begin{array}{c}\text { Mineral } \\
\text { composition } \\
\text { (\% by mass) }\end{array}$} & $\mathrm{C}_{3} \mathrm{~S}$ & 56 \\
\hline & $\mathrm{C}_{2} \mathrm{~S}$ & 25.7 \\
\hline & $\mathrm{C}_{3} \mathrm{~A}$ & 2 \\
\hline & $\mathrm{C}_{4} \mathrm{AF}$ & 16.3 \\
\hline
\end{tabular}

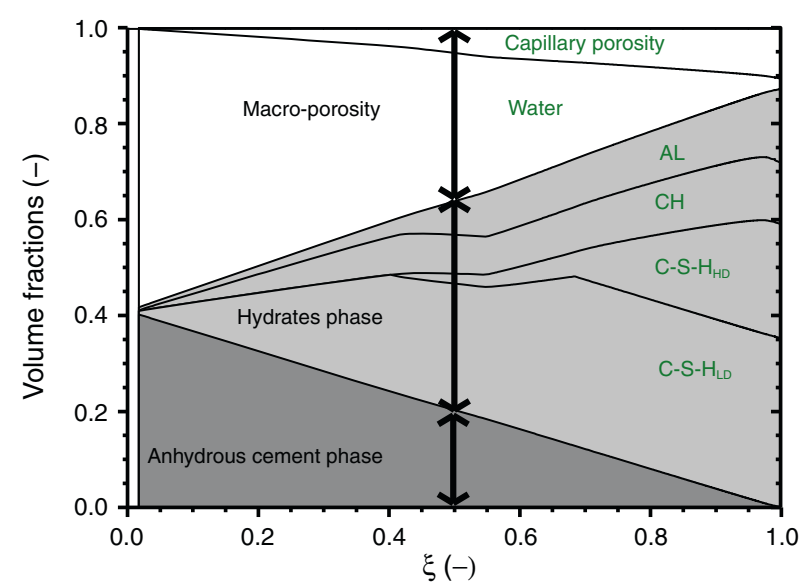

Figure 6

Evolution of the volume fractions of the components of a class $\mathrm{G}(T a b .4)$ cement paste with $w / c=0.44$ as a function of the overall hydration degree.

hydrates containing the gel porosity and the capillary porosity. At complete hydration $(\xi=1)$, all the anhydrous cement is consumed, $f_{\mathrm{C}-\mathrm{S}-\mathrm{H}}=59.1 \%$, $f_{\mathrm{CH}}=12.8 \%, f_{\mathrm{AL}}=15.3 \%$. The remaining water content $\left(f_{\mathrm{w}}=2.2 \%\right)$ and the formed capillary porosity $\left(f_{p}=10.6 \%\right)$ provide the macro porosity of $12.8 \%$. Similar trends were also obtained by Taylor [36] and Hansen [38]. It is also worth noting in Figure 7 that porosity measurements performed by the MIP technique (Mercury Intrusion Porosity) at different hydration degrees on the studied class $G$ cement [39] are consistent with the macro-porosity evolution which results from the hydration model.

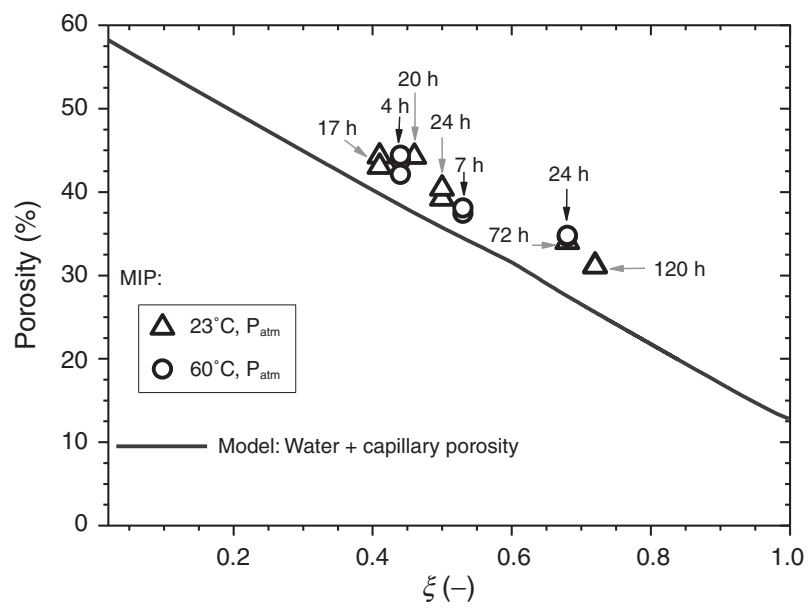

Figure 7

Evolution of the porosity of the class $\mathrm{G}$ cement paste versus the degree of hydration for two hydration conditions $\left(23^{\circ} \mathrm{C}, P_{\mathrm{atm}}\right)$ and $\left(60^{\circ} \mathrm{C}, P_{\mathrm{atm}}\right)$. Comparison of experimental results obtained from MIP technique [39] with the evolution of the volume fraction of the (water + capillary porosity) phase from the hydration model.

\section{EXPERIMENTAL RESULTS ON CEMENT PASTE}

The following experimental results have two objectives: the first one is to validate the assumptions which were used for describing the hydration process of the previous section, which provides the different volume fractions of the phases. The second one is to obtain elastic properties of the cement paste which will be compared in the following section to the results obtained by the homogenization process. In this work, all experimental results are obtained on a Class $G$ cement produced by Dyckerhoff AG which is considered to be representative of oilwell cements. Its physical properties and mineral composition are given in Table 4 . The anhydrous cement was mixed with deionized water to prepare cement paste with $w / c=0.44$.

\subsection{Characterization of the Cement Paste Hydration}

The characterization of cement paste hydration is classically performed by using calorimetric tests. It is emphasized that the cement paste which is under study must be used in field conditions which include high temperatures and pressures. So, in a first step, calorimetric tests (DSC tests) allowing to take into account the effect of these two parameters on the hydration kinetics are reported. However, these tests do not allow to recover the 
TABLE 5

Experimental conditions of DSC tests

\begin{tabular}{c|c|c|c|c}
\hline & Test 1 & Test 2 & Test 3 & Test 4 \\
\hline$T\left({ }^{\circ} \mathrm{C}\right)$ & 23 & 23 & 60 & 60 \\
\hline$P(\mathrm{~Pa})$ & $10^{5}$ & $200 \times 10^{5}$ & $10^{5}$ & $200 \times 10^{5}$ \\
\hline
\end{tabular}

hydration ratio, for which the evaluation of the heat produced during hydration must be estimated. So a second series of tests was performed by using the Langavant calorimeter. This last method allowed to recover the heat produced during hydration and therefore the hydration ratio.

\subsubsection{Temperature and Pressure Effects}

Calorimetric measurements were performed using an isotherm calorimeter (HP micro DSC VII). Such a calorimeter allows to study the temperature $(T)$ and the pressure $(P)$ effects on the hydration kinetics by following the heat flow emitted during cement paste hydration under downhole conditions. The tests conditions are summarized in Table 5.

Figure $8 \mathrm{a}$ shows that when curing temperature is elevated $\left(60^{\circ} \mathrm{C}\right)$, the three main phases of hydration duration are significantly reduced and the exothermic heat flow peak is higher than the heat flow evolution at $23^{\circ} \mathrm{C}$. Indeed, it is well known that the increase of curing temperature accelerates the hydration reactions of the cement paste $[35,40]$. However, the effect of pressure on the hydration kinetics is by far less remarkable than the one induced by the temperature (Fig. $8 b$ ). A slight shift of the peak in the heat flow reveals somehow an acceleration of the hydration reactions. The amount of heat is also slightly increased. Nevertheless this effect can be assumed to be negligible with regard to the involved contrast of pressure. The pressure effect is consequently assumed negligible in this work, and it is no more considered below.

These results provide interesting qualitative information on the hydration process, but do not provide an overall heat production which is necessary for obtaining the "calorimetric" hydration degree. So, the hydration kinetics is provided in the following section by using an alternative calorimetric set-up.

\subsubsection{Determination of Hydration Kinetics from Calorimetric Data}

The Langavant semi-adiabatic calorimeter was used to quantify the heat $Q(t)$ emitted during the exothermic chemical reactions between anhydrous cement and
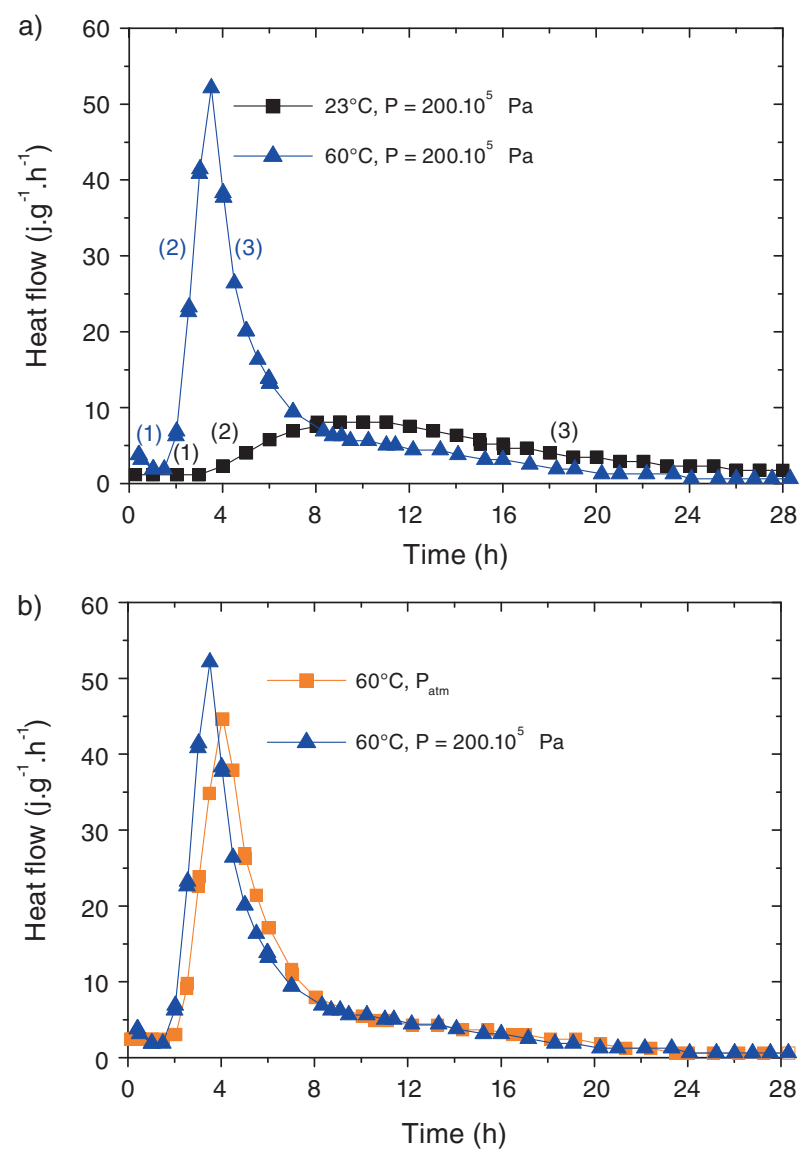

Figure 8

Time evolution of hydration heat flow per unit mass of the studied cement for two curing conditions: experimental results from isotherm calorimetric conditions with DSC. a) $23^{\circ} \mathrm{C}$ and $60^{\circ} \mathrm{C}$ under Nitrogen pressure equal to $200 \times 10^{5} \mathrm{~Pa}$. b) $60^{\circ} \mathrm{C}$ under two different pressures: $P_{\text {atm }}$ and $200 \times 10^{5} \mathrm{~Pa}$.

water. Such a calorimeter can be used only at atmospheric pressure. The overall hydration degree is then calculated by using Equation (20) where $Q(t)$ is the measured hydration heat. This measurement allows to validate the overall hydration degree obtained from the hydration model of the previous section. However, this comparison is possible at the condition to know the total heat production. This total production has been evaluated by using two different kinds of estimations coming from the literature, as shown in Figure 9, which displays predicted (from Sect. 2) and measured estimations of the overall hydration degree. The comparison between experimental and predicted values shows that the model overestimates the overall heat flow at early times, but that it recovers the main trends provided by experimental results. 


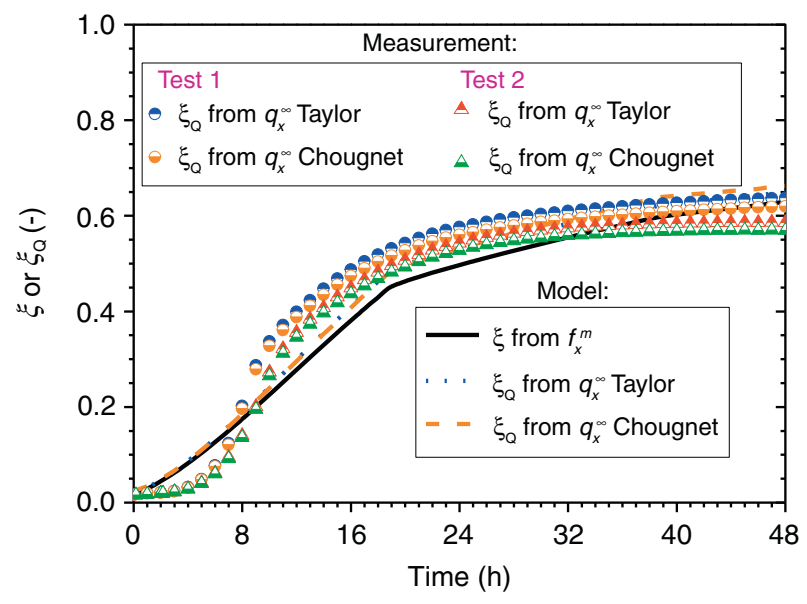

Figure 9

Comparison of the kinetics of hydration degrees $\chi_{\mathrm{Q}}$ and $\xi_{\mathrm{Q}}$ obtained from the hydration model at $23^{\circ} \mathrm{C}$ (respectively $E q$. (19) and (22)) with $\xi_{\mathrm{Q}}$ (Eq. 20) obtained from semiadiabatic measurement at $23^{\circ} \mathrm{C}, P_{\text {atm }}$.

These results must be evaluated in view of all the assumptions used in the modelling process and by considering the two types of tests which were used in this study.

There are indeed a few assumptions during the modelling of the hydration process which should need a further scrutiny:

- the use of the equation of Arrhenius to describe the temperature effect;

- Avrami's model for the normal affinity;

- Fuji and Kondo's model for the normalized affinity during the diffusion stage;

- the use of parameters of Table 2, which correspond to data coming from measurements on materials which can be different from the paste under study.

In view of these assumptions, the comparison between calorimetric data and modelling results shows that these assumptions are realistic for the cement paste under study.

In addition, the use of two kinds of calorimetric tests allowed to show that the pressure has a secondary effect on hydration compared to the temperature which strongly influences the hydration process. These results are obviously of importance for the use of the cement paste in field conditions.

\subsection{Acoustic Measurement of the Elastic Properties of the Cement Paste}

Acoustic measurements were performed using an ultrasonic instrument working in transmission mode on the cement paste cured under two different temperatures
TABLE 6

Curing conditions of the class $\mathrm{G}$ cement paste

\begin{tabular}{c|c|c}
\hline \multicolumn{3}{c}{ Curing conditions } \\
\hline$T\left({ }^{\circ} \mathrm{C}\right)$ & $P(\mathrm{~Pa})$ & Curing ages $(\mathrm{h})$ \\
\hline 23 & $10^{5}$ & 17,20 and 24 \\
\hline 60 & $10^{5}$ & $4,6,7,20$ and 24 \\
\hline
\end{tabular}

and at atmospheric pressure (Tab. 6). Samples were soaked in water then tested at atmospheric pressure and room temperature.

The device mainly consists of piezoelectric transducers for shear waves (Parametrics V153-RM) working at a central frequency of $1 \mathrm{MHz}$, which provide both shear and compression waves with only one measurement (Fig. 10). Indeed, the piezoelectric transducer emits a shear wave and a compression wave of lower amplitude which propagates more quickly in the sample than the shear wave [41]. The signal processing allows the separation between compression and shear waves.

The quantities measured are the wave propagation velocities, $v_{1}$ and $v_{\mathrm{t}}$, for longitudinal (compressive) and transverse (shear) waves, respectively. Velocities given by Equations (36) and (37) are directly related to the elastic properties of the sample and to its density by:

$$
\begin{gathered}
v_{1}=\sqrt{\frac{4 \mu+3 \kappa}{3 \rho}} \\
v_{\mathrm{t}}=\sqrt{\frac{\mu}{\rho}}
\end{gathered}
$$

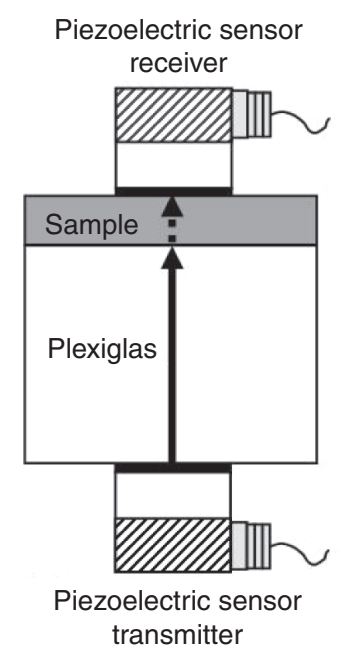

Figure 10

Experimental device used for ultrasonic modulus measurement in transmission mode. The Plexiglas cylinder is a waveguide. 


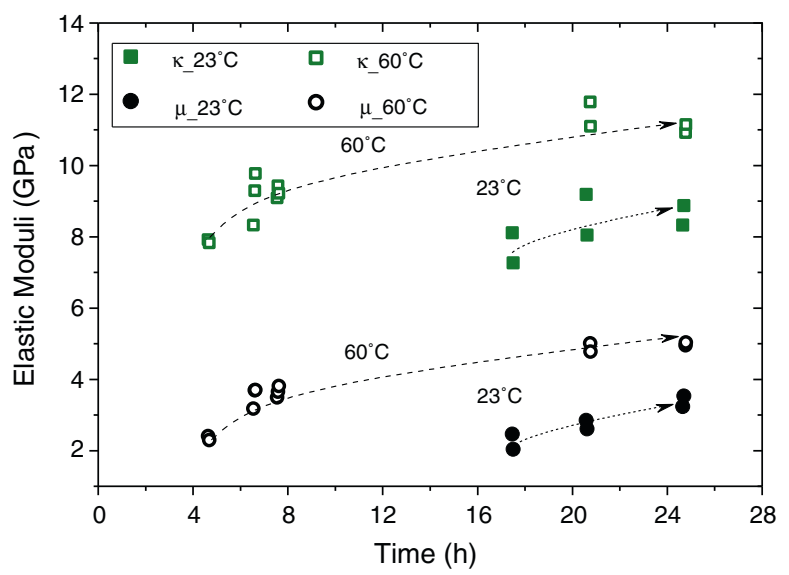

Figure 11

Evolution of dynamic elastic moduli of the class $\mathrm{G}$ cement paste with curing age. The dynamic moduli are measured by ultrasonic method at $23^{\circ} \mathrm{C}$ (solid symbols) and $60^{\circ} \mathrm{C}$ (open symbols).

The dynamic bulk $(\kappa)$ and shear $(\mu)$ moduli of the cement paste are then calculated from Equations (36) and (37) as:

$$
\begin{gathered}
\kappa=\rho \frac{3 v_{1}^{2}-4 v_{t}^{2}}{3} \\
\mu=\rho v_{t}^{2}
\end{gathered}
$$

It was not possible to measure the dynamic elastic moduli of cement pastes until the transition from a suspension containing non-cohesive solid particles to a cohesive skeleton occurs. At this time, the shear waves may propagate throughout the forming interconnected solid network [6].

Figure 11 shows the dynamic elastic moduli evolution of the studied class $\mathrm{G}$ cement paste measured at $23^{\circ} \mathrm{C}$ and $60^{\circ} \mathrm{C}(\mathrm{Tab} .6)$. These moduli quickly increase at early ages and then increase more slowly when hydration slows down. The values of the dynamic elastic moduli for the first curing age either at $23^{\circ} \mathrm{C}$ or $60^{\circ} \mathrm{C}$ are similar. Figure 11 shows also, that for the same curing age, the values of the dynamic elastic moduli at $60^{\circ} \mathrm{C}$ are higher than those obtained at $23^{\circ} \mathrm{C}$, this result being obviously due to the acceleration of the hydration process when increasing the temperature.

\section{COMPARISON BETWEEN THEORETICAL AND EXPERIMENTAL RESULTS}

Figure 12 shows the comparison between evolution of elastic moduli with time obtained experimentally and from the homogenization process. The homogenized
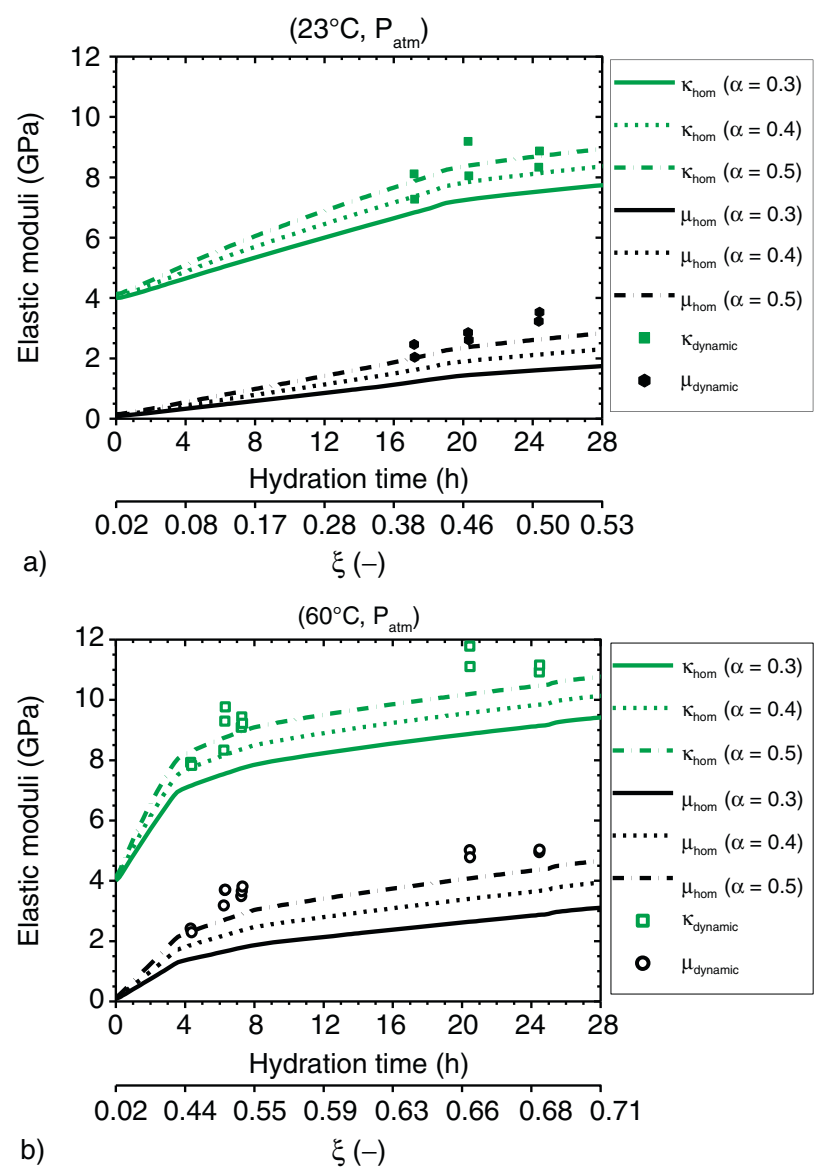

Figure 12

Early-age homogenized elastic moduli $\left(\kappa_{\mathrm{hom}}, \mu_{\mathrm{hom}}\right)$ compared with dynamic elastic moduli measured by ultrasonic method $\left(\kappa_{\text {dynamic }}, \mu_{\text {dynamic }}\right)$ a) at $23^{\circ} \mathrm{C}$ and b) at $60^{\circ} \mathrm{C}$ versus hydration time/hydration degree (class $\mathrm{G}$ cement paste, $w / c=0.44)$.

elastic moduli are obtained by introducing the different volume fractions shown in Figure 6 together with mechanical parameters given in Section 2.1, into expressions related to the use of GSC homogenization scheme in a two-step process, as previously described. Different values of parameter $\alpha$ were introduced. The results show that experimental moduli compare well with the theoretical results obtained from the highest value of $\alpha$, i.e. $\alpha=0.5$, the experimental moduli being slightly higher than theoretical ones. Obviously, the comparison between experimental results obtained by wave propagation and theoretical results coming from the hydration data combined with the homogenization process must be appreciated by taking into account the simplifications used in the process. These simplifications include:

- the use of a simplified homogenization model in which the grains of connected material are assumed spherical, knowing that this grain shape is far from real grain shapes which are very irregular; 
- the two assumptions which were used for obtaining the concentrations of each constituent in the composite sphere, which constitute certainly a simplification;

- the assumptions taken into account for modelling the hydration which were stated in Section 2.

However, despite all these simplifications, the comparison shows a good consistency between experimental and theoretical results. It shows that the main characteristics are taken into account. Indeed, the main points in this kind of modelling are to respect the connectivity of the phases and to have a correct evaluation of the concentrations of the different phases. The good consistency between experimental and theoretical results shows that these main points are respected in the whole process.

\section{CONCLUSIONS}

This paper dealt with the very early-age cement paste characterization and with the modelling of the elastic properties development under elevated temperature and high pressure frequently encountered in oil and gas wells where they have to be addressed.

Isothermal calorimetric measurements have shown an acceleration of the hydration kinetics with temperature and also a negligible effect of pressure on hydration kinetics in the range of the tested pressure. A hydration kinetics model based on chemical affinity was used to take into account the temperature effect on cement paste hydration. The model results are in a good agreement with the performed semi-adiabatic measurements of hydration heat. Then, the development of cement paste elastic properties was predicted from the use of a multiphase homogenization model, based on the evolving volume fractions of components of the hydrating cement paste determined from the hydration kinetics model and from the micromechanical properties of the multiphase cement paste at multiple scales. The elastic moduli results obtained from the multiscale homogenization approach coupled with the hydration model, at $23^{\circ} \mathrm{C}$ and $60^{\circ} \mathrm{C}$ compare well with the dynamic moduli obtained from acoustic measurements at the same temperatures.

\section{ACKNOWLEDGMENTS}

The authors are particularly grateful to Florence Adjémian (IFPEN) for fruitful discussions concerning primary cementing technique in wells and Laurent Cangémi (IFPEN) for stimulating discussions during the course of this work. The authors also want to express their special acknowledgement to Nathalie Ferrer and
Alain Rivereau (IFPEN) for their technical support during the experimental part of the study and to Hoang Duc Hieu (MSME) who strongly helped for the computations related to the GSC homogenization scheme.

\section{REFERENCES}

1 Thiercelin M.J., Dargaud B., Baret J.F., Rodriguez W.J. (1997) Cement design based on cement mechanical response, SPE Annual Technical Conf. and Exhibition (ATCE '97), San Antonio, Texas, 5-8 Oct., pp. 337-347.

2 Bosma M., Ravi K., Van Driel W., Jan Schreppers G. (1999) Design approach to sealant selection for the life of the well, 74th SPE Annual Technical Conf. and Exhibition (ATCE '99), Houston, Texas, 3-6 Oct., pp. 1-14.

3 Di Lullo G., Rae P. (2000) Cements for long term isolationdesign optimization computer modelling and prediction, 2000 IADC/SPE Asia Pacific Drilling Technology, Kuala Lumpur, Malaysia, 11-13 Sept., SPE 62745-MS, pp. 1-14.

4 Boukhelifa L., Moroni N., James S.G., Le Roy-Delage S., Thiercelin M.J., Lemaire G. (2004) Evaluation of cement systems for oil and gas well zonal isolation in a full-scale annular geometry, IADC/SPE Drilling Conference, Dallas, Texas, 2-4 March, SPE 87195-MS, pp. 44-53.

5 D’Angelo R., Plona T.J., Schwartz L.M., Coveney P. (1995) Ultrasonic measurements on hydrating cement slurries: onset of shear wave propagation, Adv. Cem. Bas. Mat. 2, 1, 8-14.

6 Boumiz A., Vernet C., Cohen-Tenoudji F. (1996) Mechanical properties of cement pastes and mortars at early ages, Adv. Cem. Bas. Mat. 3, 3-4, 94-106.

7 Lacouture J.C., Johnson P.A., Cohen-Tenoudji F. (2003) Study of critical behavior in concrete during curing by application of dynamic linear and nonlinear means, $J$. Acoust. Soc. Am. 113, 3, 1325-1332.

8 Lootens D., Hébraud P., Lécolier E., Van Damme H. (2004) Gelation, shear-thinning and shear-thickening in cement slurries, Oil Gas Sci. Technol. 59, 1, 31-40.

9 Sun Z., Voigt T., Shah S.P. (2006) Rheometric and ultrasonic investigations of viscoelastic properties of fresh Portland cement pastes, Cem. Concr. Res. 36, 2, 278-287.

10 Trtnik G., Turk G., Kavčič F., Bosiljkov V.B. (2008) Possibilities of using ultrasonic wave transmission method to estimate initial setting time of cement paste, Cem. Concr. Res. 38, 11, 1336-1342.

11 Voigt T., Shah S.P. (2004) Properties of early-age Portland cement mortar monitored with shear wave reflection method, ACI Materials J. 101, 6, 473-482.

12 Ye G., van Breugel K., Fraaij A.L.A. (2003) Experimental study and numerical simulation on the formation of microstructure in cementitious materials at early age, Cem. Concr. Res. 33, 2, 233-239.

13 Voigt T., Malonn T., Shah S.P. (2006) Green and early age compressive strength of extruded cement mortar monitored with compression tests and ultrasonic techniques, Cem. Concr. Res. 36, 858-867.

14 Reddy B.R., Santra A., McMechan D., Gray D., Brenneis C., Dunn R. (2007) Cement mechanical property measurements under wellbore conditions, SPE Drill. Complet. 22, 1, 33-38. 
15 Sanahuja J., Dormieux L., Chanvillard G. (2007) Modelling elasticity of a hydrating cement paste, Cem. Concr. Res. 37, 10, 1427-1439.

16 Torrenti J.M., Benboudjema F. (2005) Mechanical threshold of cementitious materials at early age, Mater. Struct. 38, 277, 299-304.

17 Haecker C.-J., Garboczi E.J., Bullard J.W., Bohn R.B., Sun Z., Shah S.P., Voigt T. (2005) Modeling the linear elastic properties of Portland cement paste, Cem. Concr. Res. 35, 10, 1948-1960.

18 Bishnoi S., Scrivener K.L. (2009) $\mu$ ic: A new platform for modelling the hydration of cements, Cem. Concr. Res. 39, 4, 266-274.

19 Garboczi E., Bullard J. (2009) Virtual concrete in real time, Concrete Producer 27, 4, 19-22.

20 Bernard O., Ulm F.J., Lemarchand E. (2003) A Multiscale micromechanics-hydration model for the early-age elastic properties of cement-based materials, Cem. Concr. Res. 33, 9, 1293-1309.

21 Ghabezloo S. (2010) Association of macroscopic laboratory testing and micromechanics modelling for the evaluation of the poroelastic parameters of a hardened cement paste, Cem. Concr. Res. 40, 8, 1197-1210.

22 Le Q.V., Meftah F., He Q.C., Le-Pape Y. (2008) Creep and relaxation functions of a heterogeneous viscoelastic porous medium using the Mori-Tanaka homogenization scheme and a discrete microscopic retardation spectrum, Mech. Time-Dependent Mater. 11, 3-4, 309-331.

23 Nemat-Nasser S., Hori M. (1999) Micromechanics: overall properties of heterogeneous materials, North Holland, Amsterdam.

24 Milton G. (2002) The theory of composites, Cambridge University Press, Dordrecht.

25 Zaoui A. (1997) Matériaux hétérogènes et composites, Courses of the Ecole Polytechnique, Palaiseau, France.

26 Tennis P.D., Jennings H.M. (2000) A model for two types of calcium silicate hydrate in the microstructure of Portland cement pastes, Cem. Concr. Res. 30, 6, 855-863.

27 Hervé E., Zaoui A. (1993) n-Layered inclusion-based micromechanical modelling, Int. J. Eng. Sci. 31, 1, 1-10.

28 Kell G.S. (1975) Density, thermal expansivity and compressibility of liquid water from $0^{\circ}$ to $150^{\circ} \mathrm{C}$ : correlations and tables for atmospheric pressure and saturation reviewed and expressed on 1968 temperature scale, $J$. Chem. Eng. Data 20, 1, 97-105.

29 Monteiro P.J.M., Chang C.T. (1995) The elastic moduli of calcium hydroxide, Cem. Concr. Res. 25, 8, 1605-1609.
30 Acker P. (2001) Micromechanical analysis of creep and shrinkage mechanisms, creep, shrinkage and durability mechanics of concrete and other quasi-brittle materials, Proc. of the 6th International Conference CONCREEP6, Cambridge, MA, USA, 20-22 Aug, Elsevier, Oxford, UK, pp. 15-25.

31 Velez K., Maximilien S., Damidot D., Fantozzi G., Sorrentino F. (2001) Determination by nanoindentation of elastic modulus and hardness of pure constituents of Portland cement clinker, Cem. Concr. Res. 31, 4, 555-561.

32 Constantinides G., Ulm F.J. (2004) The effect of two types of $\mathrm{C}-\mathrm{S}-\mathrm{H}$ on the elasticity of cement-based materials: results from nanoindentation and micromechanical modeling, Cem. Concr. Res. 34, 11, 1293-1309.

33 Ulm F.J., Coussy O. (1998) Couplings in early-age concrete: from material modeling to structural design, Int. J. Solids Struct. 35, 31-32, 4295-4311.

34 Pichler C., Lackner R., Mang H.A. (2006) A multiscale micromechanics model for the autogenous-shrinkage deformation of early-age cement-based materials, Eng. Fract. Mech. 74, 1-2, 34-58.

35 Escalante-Garcia J.I., Sharp J.H. (1998) Effect of temperature on the hydration of the main clinker phases in Portland cements: Part I, neat cements, Cem. Concr. Res. 28, 9, 1245-1257.

36 Taylor H.F.W. (1997) Cement chemistry, Academic Press, New York.

37 Chougnet A., Audibert A., Moan M. (2007) Linear and non-linear behaviour of cement and silica suspensions. Effect of polymer addition, Rheol. Acta 46, 6, 793-802.

38 Hansen T.C. (1986) Physical structure of hardened cement paste. A classical approach, Mater. Struct. 19, 114, 423-436.

39 Bourissai M. (2010) Comportement thermo-chimio-hydromécanique d'un ciment pétrolier au très jeune âge en conditions de prise HP/HT. Approche expérimentale et analyse par changement d'échelle, $P h D$ Thesis, University of Paris-Est.

40 Heikal M., Morsy M.S., Aiad I. (2005) Effect of treatment temperature on the early hydration characteristics of superplasticized silica fume blended cement pastes, Cem. Concr. Res. 35, 4, 680-687.

41 Franceschini A., Abramson S., Mancini V., Bresson B., Chassenieux C., Lequeux N. (2007) New covalent bonded polymer-calcium silicate hydrate composites, J. Mater. Chem. 17, 9, 913-922.

Manuscript accepted in November 2012 Published online in July 2013 


\section{APPENDIX A}

\section{COMPUTATION OF THE EFFECTIVE PROPERTIES OF A COMPOSITE MATERIAL MADE OF N ELASTIC ISOTROPIC PHASES FROM THE GENERALIZED SELF-CONSISTENT MODEL}

This appendix describes the computation of the "effective" properties of a composite medium comprising $n$ phases. The connectivity of the phases is represented by the local distribution of the phases represented by the spherically layered scheme of Figure 2.

$\kappa_{\text {hom }}$ and $\mu_{\text {hom }}$ are respectively given by [27]:

$$
\kappa_{\text {hom }}=\kappa_{n}-\frac{\left(3 \kappa_{n}+4 \mu_{n}\right) \mathbf{Q}_{21}^{(n-1)}}{3\left(\mathbf{Q}_{11}^{(n-1)} R_{n}^{3}+\mathbf{Q}_{21}^{(n-1)}\right)} ; \mu_{\text {hom }}=\frac{-B \pm \sqrt{B^{2}-4 A C}}{2 A} \mu_{n}
$$

where the matrix $\boldsymbol{Q}^{(n-1)}$ is given by:

$$
Q^{(n-1)}=\prod_{k=n-1}^{1} \frac{1}{3 \kappa_{n-k+1}+4 \mu_{n-k+1}}\left[\begin{array}{cc}
3 \kappa_{n-k}+4 \mu_{n-k+1} & 4\left(\mu_{n-k+1}-\mu_{n-k}\right) R_{n-k}^{-3} \\
\left(\kappa_{n-k+1}-\kappa_{n-k}\right) R_{n-k}^{-3} & 3 \kappa_{n-k+1}+4 \mu_{n-k}
\end{array}\right]
$$

and the coefficients $A, B$, and $C$ are given by:

$$
\begin{aligned}
A= & 4\left(1-2 v_{n}\right)\left(\left(7-10 v_{n}\right) Z_{12}^{(n-1)}+5 R_{n}^{-7}\left(1-2 v_{n}\right) Z_{13}^{(n-1)}+3 R_{n}^{-5}\left(Z_{14}^{(n-1)}-7 Z_{23}^{(n-1)}\right)\right. \\
& \left.+4 R_{n}^{-10}\left(4-5 v_{n}\right) Z_{43}^{(n-1)}\right)+20 R_{n}^{-3}\left(7-12 v_{n}+8 v_{n}^{2}\right) Z_{42}^{(n-1)} \\
B=- & \left(1-2 v_{n}\right)\left(3\left(7-15 v_{n}\right) Z_{12}^{(n-1)}+8\left(5 R_{n}^{-7}\left(1-2 v_{n}\right) Z_{13}^{(n-1)}+3 R_{n}^{-5}\left(Z_{14}^{(n-1)}-7 Z_{23}^{(n-1)}\right)\right.\right. \\
& \left.\left.+R_{n}^{-10}\left(1-5 v_{n}\right) Z_{43}^{(n-1)}\right)\right)-60 R_{n}^{-3}\left(3-v_{n}\right) v_{n} Z_{42}^{(n-1)} \\
C=-\left(1-2 v_{n}\right)( & \left.\left(7+5 v_{n}\right) Z_{12}^{(n-1)}-4\left(5 R_{n}^{-7}\left(1-2 v_{n}\right) Z_{13}^{(n-1)}+3 R_{n}^{-5}\left(Z_{14}^{(n-1)}-7 Z_{23}^{(n-1)}\right)-2 R_{n}^{-10}\left(7-5 v_{n}\right) Z_{43}^{(n-1)}\right)\right)
\end{aligned}
$$

The terms $Z_{\alpha \beta}^{(n-1)}$ are given by: $\quad+10 R_{n}^{-3}\left(7-v_{n}^{2}\right) Z_{42}^{(n-1)}$

$$
Z_{\alpha \beta}^{(n-1)}=P_{\alpha 1}^{(n-1)} P_{\beta 2}^{(n-1)}-P_{\alpha 2}^{(n-1)} P_{\beta 1}^{(n-1)}
$$

And the expressions of the matrices for the calculation of these terms are given hereafter:

$$
\begin{gathered}
P^{(n)}=\prod_{k=n}^{1} \mathbf{M}^{(\mathbf{n}-\mathbf{k}+\mathbf{1})} \\
\mathbf{M}^{(k)}=\mathbf{N}_{k+1}^{-1}\left(R_{k}\right) \mathbf{N}_{k}\left(R_{k}\right) \\
\mathbf{N}_{k}(r)=\left[\begin{array}{cccc}
r & -6 v_{k}\left(1-2 v_{k}\right)^{-1} r^{3} & 3 r^{-4} & \left(5-4 v_{k}\right)\left(1-2 v_{k}\right)^{-1} r^{-2} \\
r & -\left(7-4 v_{k}\right)\left(1-2 v_{k}\right)^{-1} r^{3} & -2 r^{-4} & 2 r^{-2} \\
\mu_{k} & 3 v_{k}\left(1-2 v_{k}\right)^{-1} \mu_{k} r^{2} & -12 \mu_{k} r^{-5} & -2\left(5-v_{k}\right)\left(1-2 v_{k}\right)^{-1} \mu_{k} r^{-3} \\
\mu_{k} & -\left(7+2 v_{k}\right)\left(1-2 v_{k}\right)^{-1} \mu_{k} r^{2} & 8 \mu_{k} r^{-5} & 2\left(1+v_{k}\right)\left(1-2 v_{k}\right)^{-1} \mu_{k} r^{-3}
\end{array}\right]
\end{gathered}
$$

